\title{
Noise reduction for digital communications - A modified Costas loop
}

\author{
János Ladvánszky ${ }^{1}$
}

\begin{abstract}
An efficient way of noise reduction has been presented: A modified Costas loop called as Masterpiece. The basic version of the Costas loop has been developed for SSB SC demodulation, but the same circuit can be applied for QAM demodulation as well. Noise sensitivity of the basic version has been decreased. One trick is the transformation of the real channel input into complex signal, the other one is the application of our folding algorithm. The result is that the Masterpiece provides a 4QAM symbol error rate (SER) of $6^{*} 10^{-4}$ for input signal to noise ratio (SNR) of $-1 \mathrm{~dB}$. In this paper, an improved version of the original Masterpiece is introduced. The complex channel input signal is normalized, and rotational average is applied. The 4QAM result is SER of $3^{*} 10^{-4}$ for SNR of $-1 \mathrm{~dB}$. At SNR of $0 \mathrm{~dB}$, the improved version produces 100 times better SER than that the original Costas loop does.
\end{abstract}

Index Terms-noise, symbol error rate, QAM, Costas loop, Hilbert filter, folding algorithm.

\section{INTRODUCTION}

Noise reduction is an important problem in communications. Digital communications are also sensitive to the noise. Effect of the noise can be detected by the symbol error rate (SER) as a function of signal to noise ratio (SNR). A possible circuit for noise reduction in digital communications is the Costas loop [1] whose original version has been developed for SSB SC demodulation. Essentially the same version can be used for 4QAM (Fig. 2).

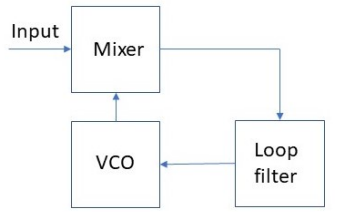

Fig. 1. Phase locked loop. The VCO output phase is related to the phase of the input signal. A simple modification can be used for frequency multiplication

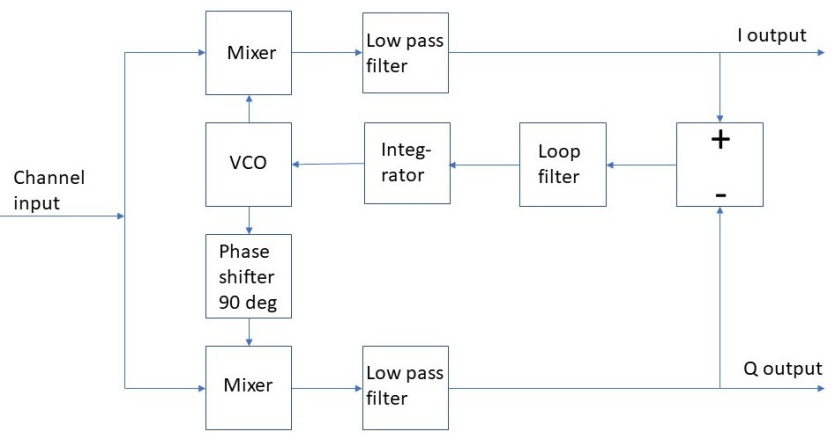

Fig. 2. Costas loop for 4QAM demodulation

${ }^{1}$ Formerly with Ericsson Hungary, Budapest, Hungary.

(e-mail: Ladvanszky55@t-online.hu)
Costas loop has been formulated from the phase locked loop (PLL, Fig. 1) [1] with introduction of separate branches for I and Q signals. A combination of the I and Q signals is used as VCO driving signal, and the two mixers have been supplied by the same VCO output signal and its phase shifted version, respectively. To understand the details of operation and its analytical treatment, please refer to [2].

The problem is that this Costas loop version is noise sensitive. Several tricks can be applied to decrease its noise sensitivity. Here we list them and apply some of them simultaneously.

Complex Costas loop

Real Costas loop is known primarily for SSB demodulation. Complex Costas loop is intended basically for QAM demodulation. From the real input signal, an analytical complex signal is formulated using Hilbert filter. Similarly, analytical version of the VCO signal is formulated. Accordingly, Complex Costas loop comprises a complex mixer and VCO signal also should be complex. In other respects, structure is the same as that for real Costas loop. Basic advantages are that BER can be better at the same value of SNR.

\section{Averaging method}

This is a method for stopping the rotation of the constellation diagram. In the VCO drive branch, signal is averaged in parallel using two different time constants. If the results are the same, then the constellation diagram stops rotation.

4th power method

Used for carrier recovery of 4 QAM. If the receiver input signal is raised to the 4 th power, then the four constellation points are transformed into the same point. That means, in one step, all information has been removed but the carrier. Advantage is very exact reproduction of the carrier. Noise sensitive.

\section{Pulse counting method}

For stopping rotation of the constellation diagram. Horizontal and vertical projections of the rotating constellation diagram contain extra steps compared to the case without rotation. Making pulses from steps by differentiation and counting and minimizing the number of steps, can be used for stopping rotation.

\section{Folding method}

Very much noise insensitive. Replaces 4 th power method. Constellation diagram is folded along an axis then the result is shifted into a symmetric position with respect to the origin. This step is repeated until one point (the carrier) remains. This method can be used for real Costas loop as well, and for 
QAM of arbitrary degree. BER of 0.01 is possible at SNR of $-4 \mathrm{~dB}$.

\section{Normalization}

Used before correlation. Complex signal is normalized exploiting that $\exp (j \omega t)$ has an absolute value of 1 . Cannot be used for real signal.

\section{Limitation}

of the VCO drive signal. Used for stopping rotation, especially in large noise. We observed that adding a large noise to the useful signal at the input of the Costas loop, significantly increases VCO drive signal thus causing rotation. Limitation of the VCO signal from below and above, limits the effect of the noise on the VCO signal.

\section{QAM sc}

It is observed that carrier in the receiver input signal interferes with the carrier produced by the Costas loop. Thus carrier (and possibly one sideband) at the receiver input has been removed by a filter.

\section{Correlation method}

Used for stopping rotation. QAM signal is produced in two different ways and the results are correlated. Deviation of the correlation coefficient from 1 is used as VCO drive signal.

\section{Differential coding}

Used for stopping rotation. Differential coding is not affected by rotation. We code the modulation signal with differential coding, and after demodulation, we use the same code for decoding [5].

\section{APPLICATION OF COMPLEX INPUT SIGNALS}

Basic version of the Costas loop is changed by inserting a block between the channel and the input of the Costas loop [2] (Fig. 3). Essence of the change is application of complex signals [2]. However, in [2], the advantages are not fully exploited. We add normalization of the input signal, that has a significant effect on noise reduction.

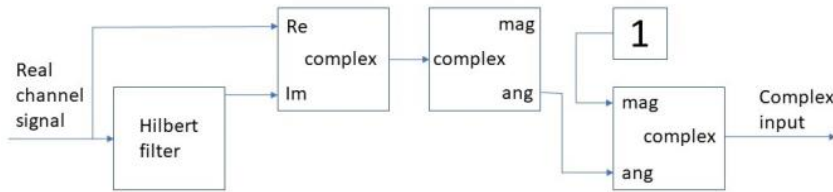

Fig. 3. Transformation of the real channel signal into a normalized complex signal

It is widely known that in order to produce an analytic signal, imaginary part of the signal can be formulated by application of a Hilbert filter for the real signal [1]. Narrowband approximation of a Hilbert filter is a 90 deg phase shifter or the corresponding delay circuit.

To remove a part of the noise from the complex signal, it is normalized by setting its absolute value to unity. Effect of application of a complex signal and its normalization has been shown in Fig. 4.

Because of insertion of the block into the Costas loop, a complex mixer must be used instead of the two real mixers, the VCO signal must also be complex and there is a modification at the beginning of the branches. We detail these modifications in Section V.

\section{THE FOLDING ALGORITHM}

Folding algorithm [3] means two foldings for 4QAM, one across the real axis and another one across the imaginary axis (Fig. 5-7). As the noise is different around all points of the constellation diagram, folding algorithm averages noise. Folding algorithm is applicable for higher order constellation diagrams as well. We consider here 4QAM only.

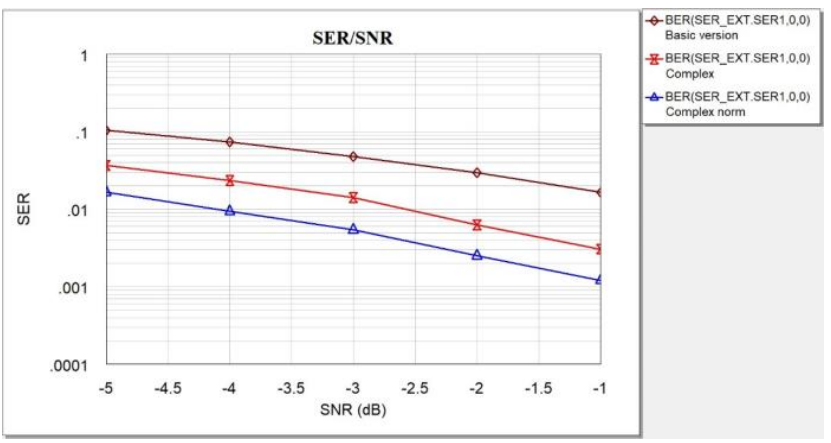

Fig. 4. Effect of application of a complex signal and its normalization on noise properties. Three curves for SER vs. SNR are shown. The upper curve is without complex signal. The middle curve is with complex signal but without normalization. Bottom curve is with normalization

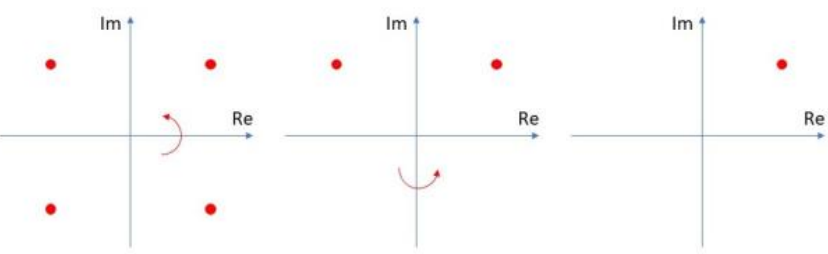

Fig. 5. Explanation of the folding algorithm for 4QAM. Left: The original 4QAM. Middle: After a folding across the Re axis. Right: After a folding across the Im axis. Only one point remains, it is perfect for carrier recovery

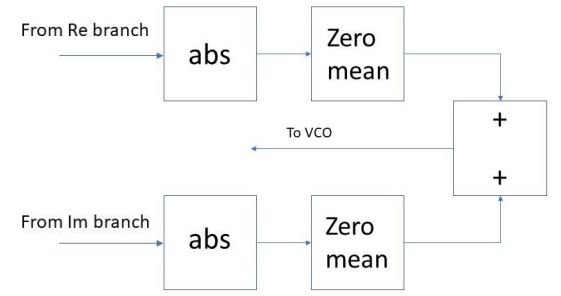

Fig. 6. Part of the system realizing the folding algorithm

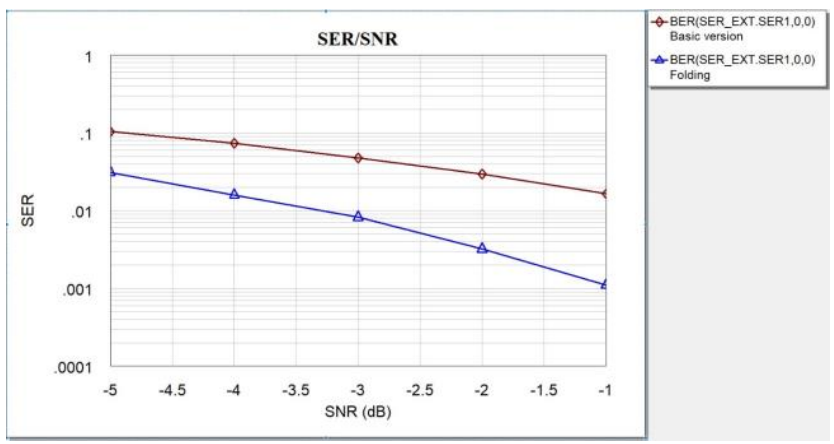

Fig. 7. Result of the application of the folding algorithm. Upper curve: Basic Costas loop, lower curve: With folding algorithm 
Noise reduction for digital communications A modified Costas loop

\section{APPLICATION OF THE ROTATIONAL AVERAGE}

Based on the right graph in Fig. 5, a new idea occurs. The noise can also be averaged after folding algorithm, if the noise in the neighborhood of the remaining constellation point is rotated around the point. We try one $90 \mathrm{deg}$ rotation as shown in Fig. 8-10, but the number of rotations can be arbitrary.
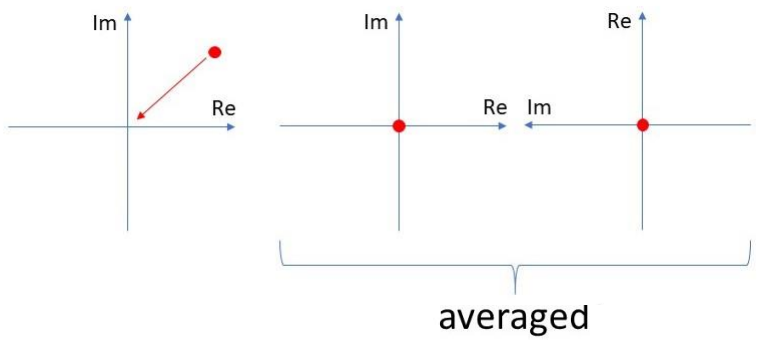

Fig. 8. Sketch of application of rotation

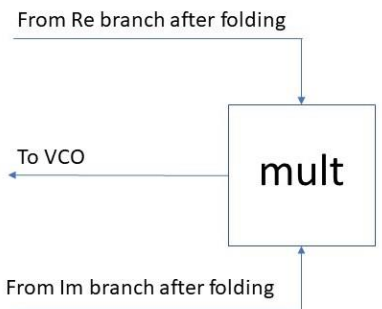

Fig. 9. Part of the system realizing rotational average. Explanation: $\left(\frac{R e+I m}{2}\right)^{2}-\left(\frac{R e-I m}{2}\right)^{2}=R e * I m$. Not jIm, this is not an error.

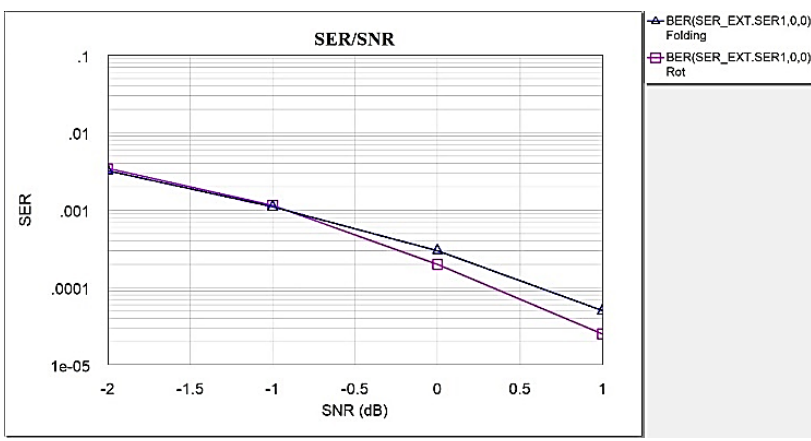

Fig. 10. Result of application of rotational average. Upper curve: Folding algorithm alone, lower curve: With application of rotational average. For bad SNR, the two algorithms offer approximately the same performance. But at slightly better SNR, the advantage of the rotational average is obvious

\section{THE IMPROVED MASTERPIECE}

First, we show the schematics including complex signals with normalization, folding, and rotational average (Fig. 11, at the end of the paper). Noise properties are shown in Fig. 12.

\section{CONCLUSIONS}

In this paper an effective method for noise reduction for 4QAM communications has been shown. Other Hungarian efforts on decreasing the effect of interference and noise are found in [6]. Our intention is application of this circuit in our version of quantum communication system.

Main statements are the new modifications of the Costas loop for achieving better noise properties: Using complex, normalized input signal (Fig. 3), the folding method (Fig. 6) and the rotational averaging (Fig. 9). These methods may result in breaking the Shannon formula: The most recent version can also work at $\mathrm{SNR}=-22 \mathrm{~dB}[7]$.

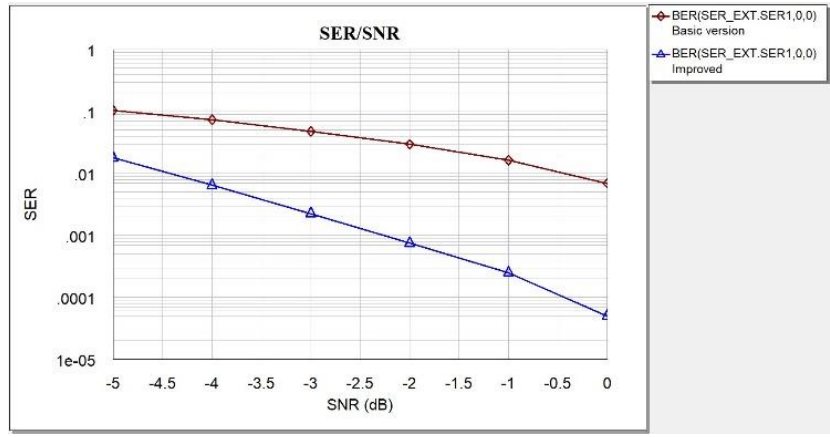

Fig. 12. Noise properties of the improved Masterpiece compared to the basic Costas loop

\section{ACKNOWLEDGMENTS}

This research was started with a discussion with Dr. András Radványi at our sailing boat get together in Balaton lake in August 2017. He put especially interesting questions, many thanks for them.

Sincere thanks are due to Dr. Benedek Kovács, last colleague of the author at Ericsson Hungary before retirement, who made it possible for the author to work at home and he participated in this work as well as co-author of the patent [4]. This research was supported by the National Research Development and Innovation Office of Hungary within the Quantum Technology National Excellence Program (Project No. 2017-1.2.1-NKP-2017-00001).

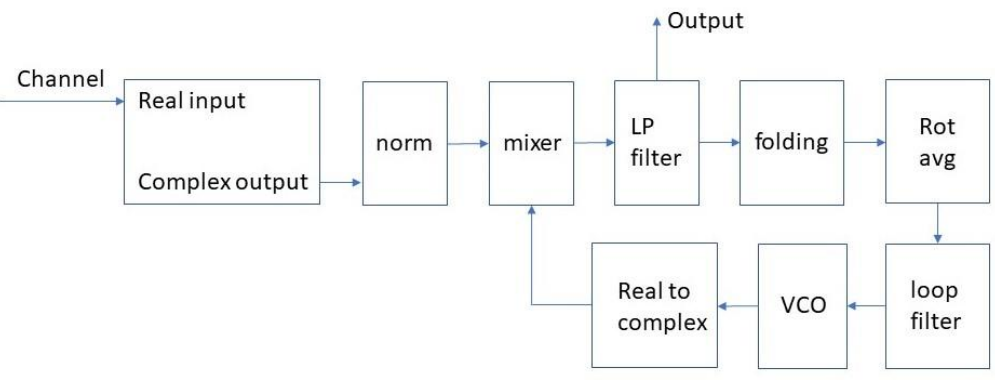

Fig. 11. Block diagram of the improved Masterpiece, a modified Costas loop 


\section{REFERENCES}

[1] J. G. Proakis: "Digital Communications", McGraw-Hill, 2001

[2] R. E. Best, N. V. Kuznetsov, G. A. Leonov, M. V. Yuldashev, R. V. Yuldashev: „Tutorial on dynamic analysis of the Costas loop”, Annual Reviews in Control 42 (2016) 27-49

[3] J. Ladvánszky: "A Costas loop variant for large noise", Journal of Asian Scientific Research, Vol. 8, No. 3, 144-151

[4] J. Ladvánszky, B. Kovács: "Methods and apparatus for signal demodulation", Ericsson patent, 2018.03.01. P74032 WO1; PCT application date: 3/1/2018; application Nr. PCT/SE2018/050198

[5] J. Ladvánszky: "A Costas loop with Differential Coding", International Journal of Contemporary Research and Review, ISSN 0976 - 4852, October, 2017|Volume 08IIssue 10

[6] A. Hilt, G. Maury, B. Cabon: "Radio-frequency interference in digital communication links", Híradástechnika/Journal on C5, 11/1999

[7] J. Ladvánszky: "A modification to the Shannon formula", Network and Communication Technologies; Vol. 5, No. 2; 2020, Dor: $10.5539 /$ nct.v5n2p1

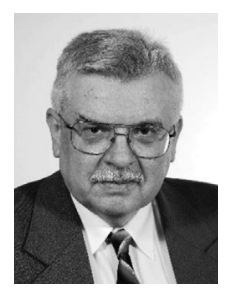

János Ladvánszky (Senior Member, IEEE) was an electrical engineer at Ericsson Hungary (MSc in 1978, „Modelling of a microwave transistor”, from the Budapest University of Technology, $\mathrm{PhD}$ in 1988, „Nonlinear, microwave circuit design”, from the Hungarian Academy of Sciences, DSc defense is just coming, „Integrated systems for optical communications", at the Hungarian Academy of Sciences). He is the world champion in 2018 in the competition on writing scientific papers in electrical engineering. Recently he got retired. His biography appeared in the 2019 edition of the book "Successful persons in Hungary", by Britishpedia. His carrier can be followed at the ResearchGate, the LinkedIn and the Facebook. At the time of the submission of this paper, he has 6 books, more than 180 publications, 14 patents, 135 citations, and about 8300 reads at ResearchGate. 